\title{
Resúmenes de Literatura Nacional
}

\section{CAMBios histopatologicos EN EL CERVIX DE MUJERES CON PARTO O CON CESAREA}

\begin{abstract}
Dres.: Miguel Bueno, Nubia Aristizábal y Humberto Restrepo
Departamento de Ginecología y Obstetricia, y Patología - Hospital Universitario del Valle, Cali
\end{abstract}

El presente trabajo se basa en las observaciones estadísticas realizadas desde 1973 por uno de los autores (M. B.), según los cuales el carcinoma del cervix es raro en mujeres que han tenido todos sus hijos por cesárea. Observaciones posteriores por el mismo autor demostraron que la edad al primer parto y el intervalo entre la edad al primer coito y la edad al primer parto, son también factores importantes asociados al carcinoma del cervix.

El presente trabajo estudia los cambios histológicos encontrados en el cervix de 100 mujeres que han tenido sus hijos por cesárea comparados con los encontrados en el cervix de otro grupo de mujeres que han tenido parto. Casos y controles son apareados por edad, edad al primer coito, y edad al primer parto o cesárea.

En cada caso y control se realiza biopsia múltiple del cervix previa prueba de Schiller y Colposcopia.

Los cambios histológicos son informados, según la nomenclatura internacional. Los datos obtenidos se analizarán estadísticamente y serán discutidos durante el Congreso.

\section{DIAGNOSTICO DIFERENCIAL EN 2.200 CASOS DE LAPAROSCOPIA EN PROFAMILIA - MEDELLIN}

Dres.: Gustavo Casas, Leonidas Rodríguez, Gabriel A. Tobón y Byron Ríos.

Se presenta una revisión de $2.200 \mathrm{ca}$ sos de laparoscopia realizados con fines diagnósticos en Profamilia - Medellín, en el período comprendido entre agosto de 1974 y julio de 1979.

Se describen las técnicas seguidas y los procedimientos realizados (biopsia, segunda punción, aspiración, etc.). Por su mayor frecuencia se identifica la patología o los síntomas que motivaron al médico a solicitar el procedimiento en: esterilidad, dolor pélvico, masa abdominal, sospecha de endometriosis, ameno- 
rrea, sospecha de embarazo ectópico, presencia de un dispositivo en cavidad abdominal, ictericia, ascitis, trauma abdominal y segunda mirada.
Se comparan los diagnósticos clínicos con los hallazgos laparoscópicos y se reconocen las bondades del procedimiento.

\title{
DIEZ AÑOS DE EMBARAZO ECTOPICO
}

\author{
Dres.: J. Ignacio Zúñiga, Federico Rivera y Jorge E. Zúñiga. \\ Hospital Universitario del Valle, Cali. - Departamento de Obstetricia y Ginecología.
}

Se revisaron 1.113 casos de embarazo ectópico en el H. U. V. en el período comprendido entre los años 1964 a 1973. Cali.

El $84.74 \%$ procedian de la ciudad de

La mayor proporción de edades eran entre 20-40 años. neral.

El $95.39 \%$ se hospitalizó en sala ge-

En la mayoría de las pacientes se encontraron los siguientes antecedentes ginecobstétricos: G 1-3, P 1-3, A O C O, con ciclos regulares y $F$. U. 4-8 semanas antes.

En su orden los síntomas más frecuentes fueron: dolor, hemorragia, vómito, lipotimia; entre los signos: defensa abdominal, palidez, hemorragia, ma- sa pélvica, hipotensión, signos de embarazo y "shock".

En el $91.80 \%$ de los casos la IDx fue de embarazo ectópico.

El $95.18 \%$ de los casos tuvo culdocentesis positiva.

En el $95 \%$ la laparatomía comprobó el diagnóstico.

Se realizó estudio patológico de 956 de los cuales el $95.39 \%$ fue concluyente para embarazo ectópico. Otros diagnósticos fueron: hematosalpinx 11 casos, salpingitis crónica 9 casos, cuerpo lúteo hemorrágico 3 casos, absceso pélvico 1 caso.

Fallecen 2 pacientes: 1 por I.R.A. y otro por broncoaspiración.

\section{SEROLOGIA DE LA TOXOPLASMOSIS}

Dres.: Roberto Vergara, Jaime Romero, Alvaro Quiroga, Enrique Gutiérrez, Dora Ramírez de

Uribe, Juan Guillermo Uribe y Max Grohl. Investigador principal: Nohora R. de Sánchez. Trabajo institucional conjunto: Clínica David Restrepo (Bogotá) - L.M.P. Laboratorio

Universitario de los Andes. Fondo Nacional de Proyectos de Desarrollo — FONADE

El trabajo consistió en el seguimiento serológico de 1.372 muieres en estado gestacional, escogidas al azar, para detectar primo-infecciones o infecciones crónicas de la toxoṕlasmosis.
Las mujeres se clasificaron en tres grupos dependiendo del trimestre en que se encontrara su embarazo: grupo A - primer trimestre, grupo B - segundo trimestre y grupo $\mathrm{C}$ - tercer trimestre. 
A partir del suero de las pacientes se practicć la prueba de inmunofluorescencia indirecta (IFI) para detectar la presencia o ausencia de títulos antiToxoplasma Gondii del tipo IgG, demostrándose así en aquellos casos positivos una previa infección con el parásito. Sueros con títulos altos (1: 1024 o superiores) se les repetía la reacción con el objeto de detectar IgM, sugestiva de una infección reciente.

Aquellas mujeres cuyos sueros presentaron una reacción positiva, se les continuó el estudio serológico con la prueba IFI cada mes para determinar perfiles serológicos que pudieran indicar, de existir un aumento de título, el desarrollo de una primo-infección y, de mantenerse igual, una toxoplasmosis crónica. En el caso de las mujeres cuyos sueros fueron negativos, el seguimiento se hizo cada dos meses para detectar aquellos casos que hicieron sospechar una infección reciente, al volverse positivos. Inmediatamente se les realizaba la IFI para IgM. De ser positiva apoyaba el diagnóstico toxoplasmosis.

A través del estudio se llevó a cabo la IFI y la inmunofluorescencia directa (IFD) a líquidos amnióticos de mujeres que hubieran presentado una serología sugestiva de toxoplasmosis, utilizando así mismo algunos líquidos amnióticos de mujeres con serología toxoplásmica negativa, como controles de las reacciones.

Fuera de las reacciones serológicas, éstas muestras fueron inoculadas en ratones de laboratorio los cuales sufrieron repeques periódicamente como posible fuente para el aislamiento del parásito. Tanto la inoculación en animales de laboratorio como la IFD se practicó a material proveniente de placenta $\mathbf{u}$ otro tejido con el mismo propósito expuesto anteriormente.

La existencia de un $44 \%$ de positividad confirmó alganas de las inquietudes iniciales del trabajo.

\title{
PRINCIPIOS CITOTOXICOS EN PLANTAS LLAMADAS EMENAGOGAS
}

\author{
Dr. José Perea Sasiain Universidad Nacional de Colombia
}

En los archivos de la encuesta del National Cancer Institute sobre principios antitumorales, el autor realizó una revisión de 362 especies vegetales consideradas emenagogas y encontró que se habían ensayado extractos de 234 de ellas y que 65 especies $(27.8 \%)$ demostraron actividad calificada como anticancerosa. Se compara este resultado con los de otros grupos estudiados previamente. Muchas plantas llamadas emenagogas $\mathrm{y} / \mathrm{o}$ abortivas contienen principios citotóxicos.

A modo de ejemplo se comparará el efecto de la momosina con el del gosipol, principios tóxicos respectivamente de la acacia forrajera y del algodonero. 